\title{
Reactie op Buy-to-let gewikt en gewogen
}

\author{
Maartje Martens ${ }^{*}$
}

In de aanloop van de gemeenteraadsverkiezingen van maart 2018 verscheen - in opdracht van de Socialistische Partij (SP) - het rapport Buy-to-let gewikt en gewogen. Het is geschreven door onderzoekers aan de Katholieke Universiteit van Leuven en de Universiteit van Amsterdam (Aalbers e.a., 2018). De SP maakt zich zorgen over de schaal waarop het fenomeen buy-to-let zich de laatste jaren manifesteert. Het is nieuw voor Nederland en het effect op de woningmarkt lijkt groot. Desondanks wordt er nog altijd maar weinig onderzoek naar gedaan. In haar opdracht wenst de SP nadrukkelijk meer inzicht te krijgen in het fenomeen buyto-let: omvang, effect en wenselijkheid ervan, plus de vraag of overheidsbeleid een rol speelt bij de groei van buy-to-let dan wel kan of zou moeten spelen.

\section{Afbakening onderzoek}

De titel van het rapport schept de verwachting dat het onderzoek nadrukkelijk over buy-to-let gaat. Maar de benadering is breder. De gehele particuliere huursector wordt geadresseerd en incidenteel ook de sociale-huursector. De reden voor deze verbreding van de ambitie wordt niet duidelijk gemaakt. De inleiding spreekt van stedelijke wooncrises, snel stijgende woonprijzen en een kenterende verhouding tussen markt en staat, waarbij de markt de laatste decennia aan belang heeft gewonnen: eerst met de groei van het eigenwoningbezit en nu met de liberalisering van de huurwoningmarkt. En over dat laatste lijkt het rapport vooral te gaan, namelijk over 'de woning als investeringsobject en verdienmodel' en de 'opmars van beleggers op de woningmarkt'. Buy-to-let wordt in dit rapport in hoofdzaak gezien als onderdeel van de particuliere huurmarkt en is daarmee losgekoppeld van de koopwoningmarkt waar de particuliere beleggers hun aankopen doen.

\section{Definitie buy-to-let}

Particuliere beleggers en investeerders ${ }^{1}$ worden onderscheiden van professionele en institutionele beleggers en investeerders. Het onderscheid is terecht, maar in de uitwerking schuilt wel een probleem. De definiëring wordt in dit rapport opgehangen aan het onderscheid particulier en institutioneel eigendom en aan de omvang van het woningbezit onder particulieren. Particuliere eigenaren met drie tot vijftig woningen zijn dan buy-to-let. Volgens de onderzoekers is het onderscheid dat zij maken internationaal gangbaar. De gebruikelijke definitie van buyto-let is echter als volgt: denoting or relating to a property bought by a person with

* Dr. ir. M. Martens is onafhankelijk woningmarktexpert Housing Analysis. 
the intention of letting it out rather than living in it (Oxforddictionaries.com). Paccoud (2017) bijvoorbeeld, hanteert eenzelfde definitie: '(...) to purchase a dwelling with the aim of putting it on the private rental market'. Ofwel, niet de grootte van de woningportefeuille is bepalend voor de eigendomsvorm, maar in welk marktsegment men actief is. Buy-to-let-beleggers opereren in een geheel ander deel van de woningmarkt dan institutionele beleggers. Ze zijn actief in de markt van, vooral bestaande, koopwoningen: zij kopen in hoofdzaak woningen van eigenaars-bewoners die willen verhuizen, en in plaats van er zelf te wonen worden deze woningen verhuurd. Buy-to-let concurreert direct met koopstarters en, afhankelijk van locatie en marktsegment, met woningeigenaren die een andere woning zoeken. Of de groep buy-to-let-beleggers zich beperkt tot particuliere personen met maximaal vijftig woningen in bezit is niet meer dan een aanname die regelmatig getoetst zou moeten worden. Het is alleszins denkbaar dat de samenstelling van de groep buy-to-let-beleggers in de loop van de tijd verandert. Alleen al daarom is het interessant te weten wie ze zijn, in welke markt ze opereren en de antwoorden te vinden op de vragen die de SP stelde: de omvang, impact en de wenselijkheid van buy-to-let.

Institutionele beleggers zijn in een heel ander deel van de woningmarkt actief, namelijk de markt voor huurwoningen. Ze zijn daarbij in hoofdzaak geïnteresseerd in de aankoop of realisatie van grote woningbouwprojecten. Zij bewegen op de markt van de nieuwbouw van huurwoningen of zijn betrokken bij projectaankopen uit portefeuilles van woningbouwcorporaties of van andere particuliere beleggers. De werkterreinen van buy-to-let- en institutionele beleggers lijken nagenoeg complementair. Het is zelfs de vraag of ze zich op dezelfde groep woningzoekenden richten. Institutionele beleggers verhuren mogelijk eerder aan huishoudens die van plan zijn zich er voor langere tijd te vestigen, terwijl in het buy-to-let-segment wellicht eerder 'passanten' te vinden zijn, zoals bijvoorbeeld studenten, toeristen of expats. Daartussen beweegt een, eveneens in het onderzoek genoemde, groep die onder de noemer professionele verhuurders geschaard zou kunnen worden en op beide markten actief kan zijn, zowel buy-to-let als (ver)nieuwbouw.

\section{Buy-to-rent als variant?}

Het voorgaande heeft betrekking op buy-to-let zoals we dat tot op heden kennen in de Britse en Nederlandse woningmarkt. Andere varianten blijken echter eveneens denkbaar. In de Verenigde Staten bijvoorbeeld heet dit fenomeen buy-torent. Onder de kopers bevinden zich niet enkel particulieren, maar ook grote beursgenoteerde institutionele beleggers zoals Real Estate Investment Trusts. Om die reden wordt deze buy-to-rent-variant in dit onderzoek geschaard onder de institutionele belegger en mist daarmee een stukje marktdynamiek.

De recente opmars van buy-to-rent begon tijdens de kredietcrisis met aankopen van woningportefeuilles op veilingen. Anders dan buy-to-let, dat tot op heden voornamelijk appartementen in steden betreft, gaat het hier om eengezinshuizen in buitenwijken en voorsteden. Deze huizen kwamen tijdens de crisisjaren terecht 
bij financiële instellingen of overheden nadat woningeigenaren hypotheeklasten niet meer konden financieren, en werden vervolgens voor spotprijzen doorverkocht. Eerst waren het vooral kleine onafhankelijke beleggers die deze eengezinswoningen opkochten, opknapten en verhuurden. Later kwamen steeds grotere delen van de portefeuilles van kleine particuliere verhuurders terecht bij megafondsen. Buy-to-rent werd big business. De bekendste is Blackstone, 's werelds grootste vastgoedeigenaar. Dit bedrijf is overigens niet alleen in de Verenigde Staten actief, maar koopt ook in bijvoorbeeld Spanje en Ierland leegstaande nieuwbouwprojecten op die sinds de kredietcrisis onverkoopbaar bleken.

Invitation Homes, een buy-to-rent-onderneming van Blackstone, ontwikkelde het buy-to-rent-concept nog een stap verder. Het is een jaar geleden begonnen met de uitgifte van single-family rental-home mortgage-backed securities (Richter, 2017). Deze worden gegarandeerd door Fannie Mae, dat door de overheid tijdens de crisis voor miljarden werd gered en nog altijd wordt ondersteund. Het is een voorlopig extreem voorbeeld van de financialisering van huurinkomsten (want daaruit worden rente en aflossing betaald op deze mortgage-backed securities) waartoe de ontwikkeling van buy-to-rent kan leiden.

De buy-to-rent-variant is eerder begonnen dan buy-to-let in Nederland en bovendien in een ander marktsegment. Desondanks zou het interessant zijn om na te gaan of in de komende jaren ook in Nederland het bezit van particuliere beleggers vaker bij institutionele beleggers of professionele verhuurders terechtkomt en mogelijk uitbreidt naar eengezinswoningen. Dat valt niet bij voorbaat uit te sluiten. Een punt van aandacht is dan wel om de definitie van buy-to-let niet langer te beperken tot particuliere personen, zoals dat ook in dit rapport het geval is.

\section{Groei van de particuliere huursector}

Het rapport van Aalbers e.a. (2018) biedt een aardig overzicht van de recente data met betrekking tot de groei van de particuliere huursector. Data over de rol van institutionele beleggers is qua nieuwbouw beperkt tot beleggingsvolumen en aankoopaantallen van corporatiebezit. De meeste informatie betreft buy-to-let, dat wil zeggen aankopen door particulieren met drie tot vijftig woningen, die gedurende de afgelopen jaren door het Kadaster is aangedragen. Groei van buy-to-let is vooral merkbaar in de G4- en studentensteden (Vries, P. de \& Brugmans, L., 2018), al zijn er ook verschillen. In Maastricht en Groningen groeit buy-to-let aanzienlijk sneller dan in Leiden of Utrecht. Data zijn echter niet recent, maar stoppen in het derde kwartaal van 2016. Er zijn indicaties dat gemeenten rondom G4- en studentensteden en soms ver daarbuiten inmiddels steeds vaker te maken krijgen met particuliere buy-to-let-beleggers, die ook daar koopstarters de markt uit prijzen (Martens, 2016 en 2018).

\section{Rol van het woonbeleid}

De oorzaak van de groei van de particuliere huursector leggen de onderzoekers voornamelijk bij het beleid, al wordt de lage rente ook genoemd (die deels bepaald 
wordt door het beleid van de Europese Centrale Bank). Een onderscheid wordt gemaakt tussen huurbeleid en beleid ten aanzien van de koopsector. Vanaf de jaren negentig krijgt de sociale sector steeds meer de rol van vangnet voor huishoudens met lage inkomens, de zogenaamde residualisering. De Vestia-affaire, verhuurdersheffing en verlaging van de maximale inkomensgrens in 2011 dwongen corporaties vervolgens verder naar hun kerntaak. Gevolg is een nieuwe vraag naar huurwoningen onder huishoudens die niet in aanmerking meer komen voor een sociale-huurwoning. In de koopsector beperkt de verscherping van leenvoorwaarden door de overheid koopstarters de toegang tot een eigen woning. Bovendien verzwakt de positie van koopstarters ten opzichte van vermogende investeerders. Veel huishoudens komen daardoor in de bekende spagaat: inkomen te hoog voor sociale huur en te laag voor een koopwoning.

Deze wijze van analyseren brengt de onderzoekers echter zelf in een spagaat. Waar scherpere leenvoorwaarden als probleem worden gezien voor de toegankelijkheid van de koopsector, is (voetnoot 41) versoepeling van de leenvoorwaarden toch niet de oplossing. Waar liggen dan wel de mogelijkheden en wat is dan eigenlijk het probleem? Het benoemen van de slachtoffers van het woningbeleid blijkt een onvoldoende kapstok voor een analyse. Er lijkt meer aan de hand dan veranderingen in het overheidsbeleid.

\section{Buy-to-let en woningprijzen}

Het rapport constateert dat het effect van particuliere beleggers en investeerders op de prijsontwikkeling van koopwoningen vooralsnog onduidelijk is. Wel wordt vastgesteld dat deze particulieren in studentensteden en met name aan de onderkant van de koopwoningmarkt de woningprijzen opdrijven. Om de vraag te kunnen beantwoorden of hierbij eventueel sprake zou kunnen zijn van een bubbel wordt over de landsgrenzen gekeken. De onderzoekers verwijzen naar literatuur over de versobering van de verzorgingsstaat, de toenemende invloed van het marktdenken en de - in Nederland - riante fiscale ondersteuning van hypotheekschuld, die in hoge mate hebben bijgedragen aan zowel de scherpe woningprijsstijgingen in de periode voor 2008 als de ongelijke vermogensopbouw tussen generaties en regio's.

De tekst hier lijkt vooral zoekende naar wat de dynamiek van de woningprijsontwikkeling zou kunnen zijn. Conclusie is dat niet kredietgroei de recente woningprijsstijgingen faciliteert en dat mede daardoor de toegankelijkheid van de koopsector voor koopstarters wordt belemmerd. Niet schuld maar eigen vermogen drijft nu de woningprijs op. Particuliere beleggers kopen met eigen geld huizen op. De onderzoekers zien dat de kans op een bubbel reëel is omdat woningprijzen weer verder uit de pas lopen met inkomens zonder dat daar via 'macroprudentiële instrumenten' als hypotheekrestricties ingegrepen kan worden.

Dat is een interessante hypothese om verder te onderzoeken. Ik zou daar twee vragen aan willen toevoegen. Allereerst om niet alleen te kijken naar de hypotheekschuld, maar evenzeer naar de huurprijsontwikkeling in relatie tot de woningprijzen. Welke samenhang is er tussen rendement en op termijn betaal- 
bare huurprijzen? Huurquotes van 40 procent of meer worden al gangbaar in de particuliere huursector. Waar ligt de grens? Daarnaast is het interessant te weten welke verhuisbewegingen buy-to-let-beleggers in gang zetten onder eigenaarsbewoners en welke rol de herbelegging van verkoopwinsten in de woningmarkt heeft op de huidige prijsvorming. Worden er nieuwe luchtbellen geblazen, ook nu het niet de koopstarters maar buy-to-let-beleggers zijn die doorstroming in gang zetten? En hoe duurzaam is deze ontwikkeling op termijn? Niet alleen overheid, ook marktpartijen reageren.

\section{Andere woningmarktdynamiek}

In 'Andere spelregels door buy-to-let' onderzoek ik mogelijke effecten van de toename van particuliere beleggers op de dynamiek van de koopwoningmarkt (Martens, 2018). Het is evident dat de recente groei van buy-to-let direct verband houdt met internationale ontwikkelingen. Denk aan het monetaire beleid van centrale banken, de lage rente, het enorme belang van vastgoed als tegenwaarde voor (de handel in) hypotheekschuld of decennia van neoliberaal woonbeleid. Interessant is dan de vraag welke dynamiek kenmerkend is voor de huidige Nederlandse koopwoningmarkt en hoe duurzaam deze ontwikkeling zal zijn? Naast extreme volatiliteit onderscheidt onze koopwoningmarkt zich internationaal al decennialang door de combinatie van uitzonderlijk hoge hypotheekschuld én een hoge mate van doorstroming waarbij de overwaarde uit de verkoop van de vorige woning deel wordt van de financiering (Martens, 2009). Overwaarde die gebakken lucht bleek zodra prijzen daalden en de doorstroming stagneerde, hetgeen samenviel met het begin van de kredietcrisis. Na zes jaar dalende woningprijzen lijkt vanaf 2014 de expansie van buy-to-let de doorstroomtreintjes nieuw leven in te blazen. Maar er zijn belangrijke verschillen met de periode vóór 2008. Niet de hypotheekschuld groeit ditmaal, maar het vermogen dat de woningmarkt instroomt, van buy-to-let beleggers tot pensioenfondsen, direct of via (hypotheek)leningen. Doorstroomtreintjes zijn nu kort en lijken vooral een inhaalvraag van door de crisis uitgestelde verhuizingen van eigenwoningbezitters. Buy-to-let beleggers bepalen steeds vaker de verkoopprijzen aan de onderkant van de markt en overbieden koopstarters, met name in universiteitssteden (verkamering, verhuur expats). De aldaar gerealiseerde verkoopwinsten beïnvloeden de bedragen die doorstromers kunnen bieden en jagen koopwoningprijzen tot ver in de regio omhoog. Nieuwe luchtbellen? Het antwoord is complex omdat de dynamiek van koop- en huursector via buy-to-let met elkaar verweven zijn geraakt. Zowel huurprijsontwikkeling (voor beleggers) als doorstroming en leenvoorwaarden (eigenaar-bewoners) zijn nu factoren van betekenis in de dynamiek van de koopwoningmarkt. We betreden hier een voor Nederland onbekend terrein.

Niet alleen woningprijzen maar ook huren stijgen fors, evenals de tekorten aan betaalbare huur- en koopwoningen. Het eigenwoningbezit onder jonge huishoudens neemt af en voor oudere woningeigenaren die willen verhuizen ontbreekt geschikt aanbod. Toch beginnen in de steden woningprijsstijgingen inmiddels af te zwakken. Tegelijkertijd is het goed denkbaar dat een aanhoudende schaarste en 
een toevloed van buitenlandse beleggers stedelijke woningprijzen weer kunnen doen stijgen. Hoe wenselijk is dit en hoe lang kan dit nog zo doorgaan voordat we in een volgende woningmarktcrisis belanden? Dit leidt tot de laatste vraag van de SP aan de auteurs van dit rapport: welke rol speelt de overheid bij de groei van buy-to-let of zou het moeten spelen?

\section{Mogelijke maatregelen woningmarkt}

Het rapport vervolgt met een overzicht van maatregelen die in andere landen ontwikkeld zijn. Dat is interessant, maar niet altijd per se relevant. Basis is een Australisch rapport dat in tien landen de changing institutions of private rental housing (Martin e.a., 2017) onderzoekt. De meeste landen zien de particuliere huursector groeien, met name door grote particuliere verhuurders zoals financiële instellingen als private equity firms en hedge funds, maar ook door Real Estate Investment Trusts of beursgenoteerde bedrijven. In Spanje en Ierland, maar ook in de Verenigde Staten gaat het om de, eerdergenoemde, buy-to-rent, aankopen uit bail-outs van financiële instellingen of overheden na de woningmarktcrisis van 2007/2008. In Duitsland is dit het gevolg van de privatisering van socialewoningbouwbedrijven. De onderzoekers signaleren een 'extreem snelle groei van dergelijke grote spelers' op de Duitse particuliere huurmarkt die ook actief beginnen te worden in Nederland.

Van alle landen die in het rapport worden vermeld, zou alleen het Verenigd Koninkrijk te maken hebben met buy-to-let-beleggers die vergelijkbaar zijn met die in Nederland. Deze worden daarbij geholpen door buy-to-let-hypotheken voor kleine particuliere verhuurders. De concurrentie met koopstarters is ook in het Verenigd Koninkrijk evident. Vooral jongvolwassenen worden weggeconcurreerd. Inmiddels worden fiscale voordelen voor buy-to-let afgebouwd, wordt een buy-tolet-hypotheek gekoppeld aan een stresstest en is de overdrachtsbelasting voor buy-to-let-aankopen verhoogd.

Terug naar eigen land wordt in het rapport een reeks van mogelijke maatregelen opgesomd. Tabel 1 geeft een overzicht van de door de onderzoekers gemaakte selectie.

Over de wenselijkheid van de voorgestelde maatregelen wordt geen uitspraak gedaan. Daardoor wordt niet beantwoord wat voor de auteurs uiteindelijk de hoofdvraag lijkt te zijn: Wat heeft de huidige particuliere woningmarkt nodig om een goed evenwicht te vinden tussen enerzijds rendement en anderzijds het voorzien in de huisvestingsbehoefte van groepen die buiten de sociale-huur- en koopsector vallen? In dat laatste ligt waarschijnlijk eveneens de grootste zorg van hun opdrachtgever: Wat is nodig om uitwassen tegen te gaan die de betaalbaarheid en toegang naar een huurwoning of een koopwoning voor het gros van de woningzoekenden belemmeren?

Al blijven antwoorden uit, dit rapport geeft zeker een belangrijke aanzet. 


\begin{tabular}{|c|c|c|}
\hline & Fiscale maatregelen & Niet-fiscale maatregelen \\
\hline Aankoop & $\begin{array}{l}\text { - Extra overdrachtsbelasting } 2^{\circ} \text { of volgende } \\
\text { woning } \\
\text { - Extra aankoopbelasting voor kopers zonder } \\
\text { binding met de regio }\end{array}$ & $\begin{array}{l}\text { - Woonplicht } \\
\text { - Economische/maatschappelijke binding met } \\
\text { de regio } \\
\text { - Stress test } \\
\text { - Kettingbeding bij verkoop corporatiebezit } \\
\text { - LTV omlaag voor } 2 \text { e of volgende woning } \\
\text { - Eisen bij nieuwbouw huur }\end{array}$ \\
\hline Exploitatie & $\begin{array}{l}\text { - Hogere belasting rekenen over } \\
\text { huurinkomsten } \\
\text { - Leegstandsboete (tegen buy-to-leave) } \\
\text { - Verhuurdersheffing ook voor kleine } \\
\text { particulieren/verhuurdersheffing afschaffen } \\
\text { - (Conditionele) verhuurdersheffing voor } \\
\text { huren boven de liberalisatiegrens }\end{array}$ & $\begin{array}{l}\text { - Inkomensgrens gereguleerde huur verhogen } \\
\text { - Liberalisatiegrens verhogen (Woningwaar- } \\
\text { deringsstelsel uitbreiden) } \\
\text { - Woningwaarderingsstelsel aanpassen } \\
\text { (o.a. WOZ uit de WWS) } \\
\text { - Strengere regels m.b.t. woningdelen } \\
\text { (en toezicht) } \\
\text { - Meer huurbescherming, hogere sancties } \\
\text { - Kraken legaliseren }\end{array}$ \\
\hline
\end{tabular}

Tabel 1 Fiscale en niet-fiscale en aankoop- en exploitatiegerichte maatregelen om investeerders op de woningmarket te reguleren

\section{Noot}

1 Het onderscheid tussen beleggers en investeerders is belangrijk bij onderzoek naar buy-to-let, maar is voor dit artikel minder relevant. Beleggers en investeerders vallen in dit artikel beiden onder de noemer 'belegger'.

\section{Literatuur}

Aalbers, M., Bosma, J., Fernandez, R., \& Hochstenbach, C. (2018). Buy-to-let gewikt en gewogen. Leuven/Amsterdam: KU Leuven/Universiteit van Amsterdam.

Martens, M. (2009). De implosie van een woningmarkt. Tijdschrift voor Volkshuisvesting 2009/6, 12-17.: 12-17.

Martens, M. (2016). Nieuwe woningmarktbubbel met nieuwe risico's door opkomst buyto-let. Me Judice, 27 oktober.

Martens, M. (2018). Andere spelregels door buy-to-let. Ruimte en Wonen, 2: 98-107.

Martin, C., Hulse, K., Pawson, H., Hayden, A., Kofner, S., Schwartz, A., \& Stephens, M. (2017). The changing institutions of private rental housing: an international review (AHURI Final Report nr. 292). Melbourne: Australian Housing and Urban Research Institute Limited.

Paccoud, A. (2017). Buy-to-let gentrification: Extending social change through tenure shifts. Environment and Planning A, 49 (4): 839-856.

Richter, W. (2017). Financialization of Rents Gets Taxpayer Guarantees. Blog 24 januari.

Vries, P. de \& Brugmans, L. (2017) Aankoop voor verhuur, Presentatie voor Expertise Centrum Woningwaarde, mei. 